\title{
Seni Perekaman Lagu O Tao Toba dan Pulo Samosir Karya Nahum Situmorang dengan Menggunakan Instrumental Akustik pada Jack's One Studio
}

\author{
EMMI SIMANGUNSONG, ${ }^{1}$ JUNITA BATUBARA, ${ }^{2}$ SOMBAMA TAMBUNAN ${ }^{3}$ \\ ${ }^{1.2 .3}$ Program Studi Musik, Fakultas Bahasa Dan Seni, Universitas HKBP Nommensen Medan, \\ Sumatera Utara, Indonesia \\ E-mail: emmi_08@yahoo.com; nitabtbara72@gmail.com
}

Artikel ini menjelaskan mengenai proses recording Di Jack's One Studio terhadap dua buah lagu tradisional Batak Toba yaitu $O$ Tao Toba dan Pulo Samosir Karya Nahum Situmorang. Ada beberapa tahapan yang digunakan instruktur Jack's One Studio dalam recording musik instrumental akustik pada saat perekaman yaitu: Composing, Arrangging, Recording, Mixing, dan Mastering. Ini juga tidak hanya untuk deskrip tetapi menemukan dan mengetahui konsep dan aplikasi dalam pengerjaan perekaman dengan menggunakan musik program komputer khususnya untuk instrumental akustik.

\section{The Art of Recording of $O$ Tao Toba and Samosir Pulo Songs by Nahum Situmorang Using Acoustic Instrumental at Jack's One Studio}

This article explains the process of recording At Jack's One Studio for two traditional Batak songs enttitled $O$ Tao Toba and Samosir Pulo by Nahum Situmorang. There are several stages that are applied by Jack's One Studio's intructors in recording acoustic instrumental music during the recording process, namely: composing, arranging, recording, mixing, and mastering. The purpose of the study is not only focused in the matter of description, but it is also conducted in order to find out and to observe the concepts and applications within a process of recording using computer program music especially for acoustic instrumental.

Keywords: Recording, acoustic instrumental, O Tao Toba \& Pulo Samosir, Jack's One Studio

Di Indonesia, khususnya di kota Medan, industri rekaman menjadi media bisnis yang telah berkembang sejak lama. Musik yang diproduksi biasanya berbagai jenis yaitu: musik dangdut, pop, instrumental bahkan musik yang bernuansa etnis. Para seniman atau komposer menciptakan musik sedemikian rupa untuk dapat diterima dan dipasarkan. Salah satu tempat yang mampu menampung segala aspirasi musik yang dapat diterima oleh masyarakat pada umumnya yaitu recording (rekaman musik).

Recording ditemukan pertama kalinya pada satu abad yang lampau, dan hingga saat ini recording berada pada era digital. Tujuan utama recording mampu merekam segala jenis suara, baik suara manusia (vokal) maupun alat musik seperti gitar, bass, drum, saxophone, keyboard. Gunanya untuk menghasilkan demo rekaman yang ditampilkan dalam variasi yaitu: bentuk format kaset, CD, file midi (MP3) (Bangun, 2005:99).

Musique Concrete adalah satu-satunya komposisi pertama musik elektronik yang membawa jenis musik ini untuk patut diperhatikan pada abad ke 20. Pertama kali musik elektronik dilakukan oleh seorang teknisi radio dan televisi di Prancis (the Radiodiffusion-television Francaise) yaitu Pierre Shaeffer merekam karyanya dengan menggunakan 
material phonograph disc, mesin recording, pengukur air, petir langkah kaki, hembusan nafas, jam, batu dan berbagai bahan lain yang terdapat di lingkungan sehari-hari. Kemudian bunyi tersebut disusun secara merakit seperti saling menimpa dan saling mengisi terhadap bunyi-bunyi yang lain, dan dimainkan secara berkelanjutan dan berulang. Bentuk awal juga dimainkan dengan perubahan tempo/kecepatan. Pada tahun 1930-an sebenarnya cara ini telah lebih dahulu dilakukan oleh Hindemith dan Toch (Godfrey, 1993:111).

Pada tahun 1940-an dimulai eksperimen dengan menggunakan multitrack recording (seperti gambar 1) yang terus berkembang menjadi lebih rumit hingga tahun 1960-an. Dengan adanya multitrack recording, teknik merekam dengan memisahkan grup artis dapat dilakukan. Efek lain yang ditimbulkan oleh multitrack recording ini adalah munculnya suara stereo. Pada tahun 1930-an mulai bereksperimen dengan merekam menggunakan dua microphone, dua amplifier, dan dua speaker yang menyebabkan efek aural yang menyenangkan (Pratiwie, 2009: 1).

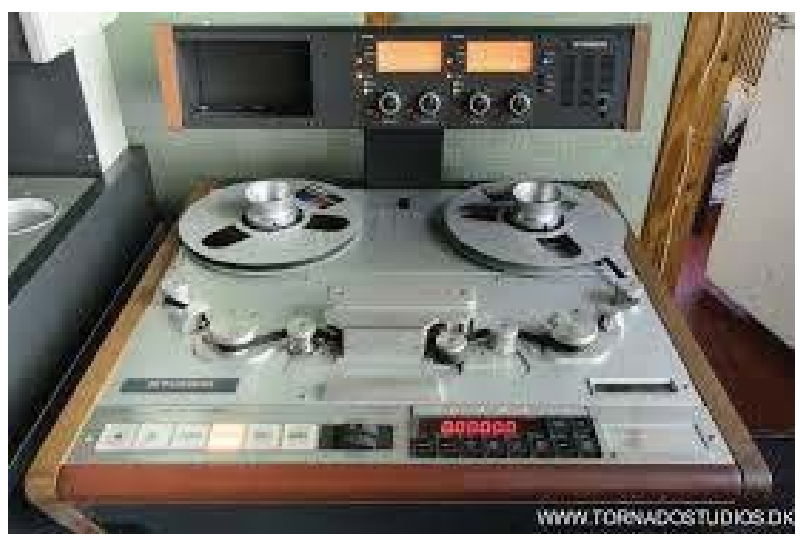

Gambar 1. Multitrack Recording

(Sumber: www.tornadostudios.com)

Mulai tahun 1980-an teknologi digital recording mulai berkembang. Tahun 1984 Sony memperkenalkan Compact Disk CD yang berbentuk seperti cakram kecil dengan lubang di tengahnya. Ide dari pembuatan $\mathrm{CD}$ ini adalah merampingkan bentuk media penyimpan musik populer selama ini yaitu kaset yang dirasa terlalu besar (Pratiwie, 2009: 5). Sejarah singkat rekaman musik di Indonesia sudah dikenal pada tahun 1940-an. Perkembangan rekaman musik di Indonesia berawal dari dua tempat yaitu Lokananta di Surakarta dan Irama di Menteng Jakarta. Lokananta berfokus memproduksi lagulagu daerah, sementara Irama berfokus memproduksi lagu-lagu hiburan. Perkembangan rekaman musik terjadi pada akhir tahun 1950-an hingga memasuki tahun 1960-an. Lokananta adalah perusahaan rekaman yang dibiayai oleh pemerintah Indonesia; berdiri tahun 1956, berlokasi di Surakarta, Jawa Tengah. Dari awal berdiri, Lokananta mempunyai dua tugas besar, yaitu produksi dan duplikasi piringan hitam dan kaset (Hsutadi, 2010: 1-2).

\section{Tahapan Recording Pada Studio Rekaman}

Dalam proses recording lagu mempunyai masingmasing 'seni' tersendiri pada studio rekaman untuk memperoleh hasil sesuai dengan kebutuhannya. Ada beberapa tahapan yang harus diperhatikan dalam 'seni' recording lagu pada studio rekaman yaitu: 1). composing (proses komposisi), 2). arrangging (proses arransemen), 3). recording (proses perekaman), 4). mixing (percampuran), dan 5). mastering (pemolesan) (Petra 2012: 1-2).

\section{Composing (proses komposisi)}

Composing adalah proses awal dari produksi sebuah lagu (musik). Didalam proses Composing terdapat hal yang menyangkut mencari ide, menulis lagu, membuat melodi vokal atau musik. Hal ini merupakan pondasi awal yang sangat berpengaruh pada hasil akhir nantinya.

\section{Arrangging (proses aransemen)}

Arrangging adalah proses membuat/mengubah musik yang belum ada maupun yang ada menjadi komposisi musik yang baru. Pada saat inilah peran seorang Composer musik sangat dibutuhkan untuk mengenal gendre musik, alat musik yang akan digunakan, intro musik, reff, dan tempo untuk kemudian direkam.

\section{Recording (proses perekaman)}

Recording adalah proses merekam suara atau audio. Pada tahap ini peran Home Recording mulai tampak (bagi yang merekam menggunakan Home Recording). Dalam proses recording yang perlu dilakukan adalah masalah teknis yakni: routing alat rekaman, mengatur gain alat, setting alat, dan proses rekam itu sendiri. 


\section{Mixing}

Mixing merupakan proses pencampuran dari tiap track suara baik instrumen, vokal, dan lain sebagainya dari hasil recording (Perekaman). Pada tahap ini dilakukan proses balancing, memberi effect pada hampir tiap track, equalisasi per track, automation per track.

\section{Mastering (pemolesan)}

Mastering adalah tahapan akhir pada proses recording di studio rekaman. Pada tahap ini terjadi pemolesan keseluruhan baik itu vokal maupun musik yang sudah direkam, melakukan equaliasai kembali, mengkompress, limiting, menaikkan gain, menghilangkan noise, mengurangi kesalahankesalahan dari hasil mixing, dan lain sebagainya.

Perkembangan teknologi juga memiliki dampak yang sangat signifikan terhadap industri musik. Ini terlihat semakin murah dan mudahnya untuk proses rekaman maupun editing tentunya menjadi faktor yang menentukan bahwa kini rekaman dapat dilakukan di mana saja. Industri rekaman dan musik apabila dilihat dari perspektif ekonomi politik merupakan sistem yang elemen-elemennya saling terkait. Di dalam sistem industri musik dan rekaman terdapat berbagai kepentingan, yang di jalankan secara bersama dan seimbang yang bertujuan untuk memperjuangkan kepentingan masingmasing dalam industri musik tersebut (Pramudyanto 2013: 64-65).

Berdasarkan hasil wawancara dengan Jekonia Sembiring, salah satu pengusaha studio rekaman di Kota Medan pada tanggal 29 Juni 2015, beliau juga mengatakan bahwa ada tahapan yang dilakukan dalam proses recording sebuah lagu dalam bentuk instrumental untuk mendapatkan hasil yang baik yaitu: Composing, Arrangging, Recording, Mixing, dan Mastering. Peran seorang instruktur rekaman juga sangat penting pada studio rekaman. Karena fungsi instruktur pada studio rekaman sebagai pengarah musik atau lagu pada saat direkam. Baik atau tidaknya hasil suatu rekaman musik, tergantung ditangan seorang instruktur.

Beliau juga mengatakan bahwa banyak pasang surut yang terjadi di dunia rekaman, khususnya dunia rekaman di Kota Medan. Menurut penuturan Jekonia Sembiring selaku pengelola/pemilik Jack's One Studio bahwa Jack's One studio berdiri pada tahun 2000 yang lalu. Jack's One Studio mengawali karirnya di industri rekaman dengan menggunakan tape recorder dibantu dengan controller dalam perekaman musik secara manual. Dengan berkembangnya kemajuan teknologi dalam bidang recording maka sangat diperlukan software untuk mempengaruhi kualitas produksi. Di Kota Medan sendiri permintaan pasar tentang musik sangat banyak khususnya lagu-lagu yang bersifat etnis atau kedaerahan. Ini memicu para penyanyi untuk melakukan recording. Dengan melihat daya tarik masyarakat yang begitu antusias tentang musik khususnya musik yang bernuansa etnik, para komposer juga berinisiatif mengubah vokal yang diiringi musik digantikan oleh ensambel instrumen musik baik yang dibuat secara digital ataupun instrumental akustik tanpa menggunakan syair.

Dengan adanya proses dalam recording, maka dilakukan proses recording di studio Jack's One Studio dengan sampel lagu yang berjudul $O$ Tao Toba dan Pulo Samosir dari karya Nahum Situmorang. Komposisi musik instrumental yang dipilih untuk mendukung recording tersebut adalah instrumen musik saxophone alto sebagai pembawa melodi, instrumen musik tradisional yaitu sulim, gitar bass, gitar akustik, dan cazon sebagai pembawa ritem konstan. Ketertarikan dalam memilih sampel lagu O Tao Toba dan Pulo Samosir karena lagu-lagu tersebut yang sudah popular, sering dinyanyikan baik dalam bentuk kaset, $\mathrm{CD}$ dan VCD, sehingga mempermudah dalam pentranskripsian dari bentuk audio ke visual (tulisan). Selain daripada itu, kedua-dua lagu tersebut memiliki kontur atau garis melodi yang berbeda dan irama musik yang berbeda, yaitu kontur Statis \& Terraced pada lagu O Tao Toba dengan irama musik slowfox dan kontur Pendulous pada lagu Pulo Samosir dengan irama musik slow-calypso.

Dalam sebuah proses transkripsi lagu diperlukan analisis untuk menguraikan hasil struktur musik lagu yang menjadi sampel. Dengan menggunakan teori William P Malm yang mengatakan bahwa untuk mendeskripsikan hasil analisis lagu adalah melalui tangga nada (dilihat dari nada pokok/modal) (1964:8), nada dasar (melihat nada mana yang sering digunakan dan nada mana yang jarang digunakan dalam lagu tersebut) (Nettl, 1964:164), interval, wilayah nada (jarak antara nada terendah sampai ke nada yang tertinggi), frekwensi 
pemakaian nada, kadens (pergerakan akord dari suatu frase lagu ke akhir dari lagu), formula melodi (bentuk), Malm (1967:80) dan kontur (garis melodi dalam sebuah lagu), Malm (1967:8). Dari hasil analisis yang telah dilakukan maka yang terdapat pada lagu $O$ Tao Toba dan Pulo Samosir meliputi tangga nada, wilayah nada, kadens, formula melodi dan kontur lagu (dapat dilihat pada tabel 1):

Tabel 1: Kesimpulan Analisis Tangga nada, wilayah Nada, kadens, formula melodi \& kontur lagu

\begin{tabular}{|l|l|l|l|l|l|l|}
\hline No" & Judul Lagu" & Tangga nada" & Wilayah Nada" & Kadens" & $\begin{array}{l}\text { Formula } \\
\text { Melodi" }\end{array}$ & Kontur Lagu" \\
\hline 1." & O Tao Toba" & Diatonik" & C-D1" & $\begin{array}{l}\text { Nada C } \\
\text { diakhiri } \\
\text { Nada C" }\end{array}$ & Stropic" & $\begin{array}{l}\text { Statis Terraced " } \\
\text { Te }\end{array}$ \\
\hline 2." & Pulo Samosir" & Diatonik" & G-C1" & $\begin{array}{l}\text { Nada G G } \\
\text { diakhiri } \\
\text { nada C" }\end{array}$ & Stropic" & Pendulous" \\
\hline
\end{tabular}

Software Musik yang Digunakan Pada Jack's One Studio

Software komputer adalah perangkat lunak komputer untuk mengkontrol perangkat keras, dan dapat juga diartikan sebagai data yang diprogram dan disimpan secara digital dalam bentuk aplikasi, termasuk program komputer, dokumentasinya, dan berbagai informasi yang bisa dibaca dan ditulis oleh komputer. Banyak software musik yang digunakan pada studio rekaman diantaranya: FruityLoop Studio 8.0, software Windows 7 sebagai sistem operasi, software Nuend 06, software EZdrumer, software GearBox, software Reason, software Melodyne, dan software Adobe Audition CS6.

\section{Fruity Loop Studio 8.0}

FruityLoop Studio 8.0 adalah software komputer yang berfungsi untuk membuat dan mengolah musik secara digital. Di sebut musik digital karena musik yang diciptakan dan diarransemen adalah hasil dari permainan komputer tanpa melalui rekaman alat musik konvensional. Keunggulan FruityLoop Studio 8.0 adalah adanya hasil sound yang karakternya mendekati karakter sound yang di hasilkan oleh bunyi sound yang realistis. Seperti suara drum yang dihasilkan cukup mendekati bunyi drum secara konvensional. Fruity Loop Studio 8.0 memungkinkan seseorang untuk bisa membuat musik yang benar-benar fantastis dan tidak realistis, bahkan tidak bisa ditirukan oleh musisi lainnya (Sumendong, 2012:1-2). Software ini sering digunakan di berbagai studio rekaman di kota Medan termasuk di studio Jack's One karena pembuaatan/program musik yang simpel dan aplikasi yang sangat mudah digunakan.

\section{Software Nuendo}

Nuendo adalah salah satu software untuk perekaman yang diproduksi oleh Steinberg Gmbh (Nurdiana, 2012:1-2).

\section{Software EZ Drumer}

Software EZ drumer merupakan software virtual instrumen yang biasa dipakai oleh musisi atau sound enginer untuk membuat instrumen musik yang mereka inginkan. Software ini cukup mudah digunakan dibandingkan dengan software virtual instrumen sejenis karena software ini hanya memberikan fitur dasar seperti pengaturan volume dan reverb (Mangkat, 2013: 2-3).

\section{Software Gear Box}

Software Gear Box berfungsi sebagai simulator amplifier dan effect untuk gitar dan bass (Indaq, 2012:1).

\section{Software Reason}

Reason adalah sebuah virtual instrumen, dimana konsep reason sebenarnya sederhana yaitu sebuah software dimana seorang musisi dapat memperoleh apapun yang ia perlukan untuk membuat sebuah lagu. Reason menganut sistem Closed Architecture, dimana Propellerhead Software tidak mengundang pihak ketiga untuk membuat plugins bagi Reason. Hal ini lain dengan apa yang terjadi di dunia VST maupun RTAS (lihat di komputer edisi-edisi sebelumnya). Dalam platform ini banyak sekali plugins yang dibuat oleh pihak ketiga.

Sistem tertutup ini membuat Reason memiliki komponen yang terbatas, karena tidak memiliki plugins, 
namun hal ini sekaligus menjadi kekuatan Reason. Karena tidak menerima plugins dari pihak ketiga, artinya Reason terbebas dari kemungkinan crash yang disebabkan ketidakcocokkan kode pemrograman antara plugins dan host. Hal ini membuat Reason sangat stabil, hampir bisa dikatakan tidak pernah crash, sesuatu yang sangat diperlukan oleh sebuah program musik profesional (Purnomo, 2009: 1).

\section{Software Melodyne}

Software Melodyne adalah salah satu software yang berfungsi mengediting masalah pitch dan rhythm suatu data audio baik itu vokal maupun suara instrumen yang telah direkam. Melodyne dapat mendeteksi nada setiap not dalam file audio bahkan bisa mengubahnya menjadi not berbeda (dengan adanya transpose). Hal tersebut terlihat dari kualitas hasil transpose yang tetap baik. Kebanyakan software audio editing lainnya memang dapat membuka file audio, tetapi software itu sendiri sebenarnya 'tidak mengerti' apa isi data tersebut. Kita sebagai pemakai harus menebak sendiri, baik dari gambar atau dari bunyinya, not apa yang sedang kita edit (Redyafrians, 2011:1-3).

\section{Software Adobe Audition CS6}

Teknologi audio saat ini sudah demikian maju. Terbukti bahwa banyak penikmat musik telah mengedepankan kualitas sound. Tidak asal keluar, komposisi sound yang berkualitas memiliki fungsi dan nilai seni yang lebih berkelas. Kecanggihan teknologi editing audio digital mendukung semuanya itu, perangkat hardware pun mengikutinya dan tersedia dengan harga yang semakin murah. Untuk menghasilkan sebuah komposisi audio digital professional, diperlukan aplikasi pengolah audio yang handal pula, salah satunya adalah Adobe Audition (Wahana Komputer, 2014: III-IV).

\section{BIOGRAFI NAHUM SITUMORANG DAN KARYA-KARYANYA}

Dalam Kamus Besar Bahasa Indonesia, disebutkan bahwa biografi adalah riwayat hidup seseorang yang ditulis oleh orang lain (Pustaka, 2003:145). Dalam bidang sastra misalnya melalui buku Antologi Biografi Pengarang Sastra Indonesia (1999:3-4) dijelaskan bahwa biografi adalah suatu teori yang dipergunakan untuk mendeskripsikan hidup pengarang atau sastrawan. Nahum Situmo
Nahum turut dalam barisan Perintis Kemerdekaan rang lahir di Sipirok pada tanggal 14 Februari 1908, putra dari Guru Kilian Situmorang, sebagai anak ke-5 dari 8 bersaudara. Karirnya sebagai penyanyi dimulai sejak masih duduk di bangku sekolah dasar, Pendidikannya yang terakhir adalah sekolah guru Kweekschool di Lembang, Bandung, lulusan tahun 1928 (Panisioan, 2012:1).

Sebagai anggota Kongres Pemuda pada tahun 1928 dan mengikuti sayembara untuk menciptakan lagu kebangsaan. Sayembara ini dimenangkan oleh WR Supratman, sementara Nahum mendapatkan tempat kedua. Nahum mulai bekerja pada tahun 1928 pada Sekolah Partikelir Bataksche Studiefonds di Sibolga hingga tahun 1932 (Situmorang, 2010: 2).

Tahun 1932 kemudian pindah ke Tarutung untuk bergabung dengan abangnya Guru Sophar Situmorang dan mendirikan HIS-Partikelir Institut Voor Westers Lager Onderwijs yang berlangsung hingga kedatangan Jepang pada tahun 1942. Seumur hidupnya Nahum tidak pernah bekerja sebagai pegawai pemerintah Belanda. Semasa mudanya ia telah berkali-kali memenangkan sayembara lagu-lagu, antara lain Sumatra Keroncong Concours di Medan (1936) dan ketika itu rombongan Nahum Situmorang dipimpin oleh Raja Buntal Sinambela, Putra Sisingamangaraja XII (Situmorang, 2010: 2).

Lagu-lagu populer Nahum Situmorang pada era 1940-an bertemakan tentang cinta, patriotisme, pengorbanan, kesedihan nostalgia, kerinduan terhadap kampung halaman, keindahan alam, dan tentang nasihat. Lagu-lagu yang beliau ciptakan antara lain: Nunga Lao Ro Muse dengan irama rumba, Nahinali Bangkudu, dengan gaya andung, Sega Na Ma Ho dengan irama country Sai Tu Dia Ho Marhuta, dengan irama waltz, Sapata Ni Napuran dengan irama keroncong dan masih banyak lagu lainnya (Hodges, 2009: 133).

Secara khusus Nahum Situmorang (1908-1969) telah menciptakan sekitar 140 lagu-lagu Tapanuli dalam kurun waktu 30 tahun, yaitu antara tahun 1932-1962. Masa 1950-1960-an merupakan masa yang paling aktif untuk Nahum dalam mencipta. Rura Silindung yang alamnya sangat indah dengan kota Tarutung yang dikelilingi Bukit Barisan memberikan lebih banyak ide dan kesempatan untuk menciptakan lagu-lagu Tapanuli. Lagu-lagunya 
masih sangat populer sampai sekarang di kalangan orang Batak Toba maupun masyarakat umum dan menginspirasi banyak pencipta lagu-lagu Tapanuli pada masanya dan para penerusnya saat ini (Hodges, 2009: 134-135).

Hingga saat ini karya Nahum Situmorang masih tetap exsist di kalangan pendengar musik Batak. Pernyataan tersebut dapat disimpulkan penulis karena banyak penyanyi Batak yang masih membawakan karya Nahum Situmorang dalam bentuk solo, duet bahkan trio. Viktor Hutabarat dan Joy Tobing adalah salah satu penyanyi solo yang sering membawakan karya Nahum Situmorang, Trio Ambisi yang membawakan Karya Nahum Situmorang pada album rekaman 10 Karya Nahum Situmorang. Karya Nahum Situmorang yang sangat hits sampai saat ini adalah yang berjudul Pulo Samosir dan Tao to Toba.

\section{Seni Perekaman Mixing Recording di Jack's One Studio}

Jekonia Sembiring merupakan salah satu instruktur dalam rekaman dan beliau memiliki studio rekaman yang bernama Jack's One Studio yang beralamat di Jalan Karya Sembada nomor 260 (Koserna Padang Bulan) Medan. Persiapan dalam seni atau proses rekaman yang dilakukan oleh Jekonia adalah: (1) Alat perekam, (2) Ruangan studio, dan (3) Alat musik yang digunakan. Menurut hasil perbincangan dengan Jekonia Sembiring pada tanggal 29 Juni 2015 di Jack's One Studio, beliau mengatakan bahwa peralatan perekam pada studio Jack's One Studio terbagi menjadi dua bagian yaitu perangkat keras dan perangkat lunak. Perangkat keras adalah alat yang digunakan untuk mengolah data. Dalam hal ini perangkat keras yang dimaksud adalah komputer yang dibutuhkan untuk membangun serta mengimplementasikan system tersebut. Komputer yang dipakai oleh Jack's One Studio merk Intel dengan Mainboard Msi (P45), Processor (Intel Pentium Quad Coret), Ram 4 Gb OCZ, Speaker Yamaha Flat, Hardisk 500 Gb,VGA On Board, CD-RW Samsung, Monitor LG, Soundcard Tone Port UXII Line 6 Keyboard dan mouse (PS2 Standard), input media (M-audio controller) input media (Microphone Shure).
Jack's One Studio banyak memegang proyek rekaman musik tradisional, misalnya: musik Batak Toba, musik Batak Karo, musik Batak Pak-pak, musik Batak Simalungun, dan Nias. Studio rekaman yang dikatakan memiliki standard adalah studio rekaman yang memiliki fasilitas memadai yakni dilihat dari alat-alat/software yang digunakan dalam proses rekaman baik itu format Solo pada penyanyi, duet, trio, kuartet, paduan suara, bahkan format band, sesuia dengan permintaan konsumen.

Microphone adalah suatu alat yang berfungsi untuk mengubah energi-energi akustik (gelombang suara) menjadi sinyal listrik. Microphone sering digunakan digunkaan di tempat-tempat seperti radio, studio rekaman dan lain sebaginya. Di studio rekaman mikrophone berfungsi sebagai penangkap suara vokal maupun instrumen yang akan direkam. Kualitas dari microphone yang digunakan dalam rekaman menjadi salah satu penentu hasil rekaman. Jack's One Studio memakai microphone jenis kondensor merk Shure (seperti pada gambar 2).

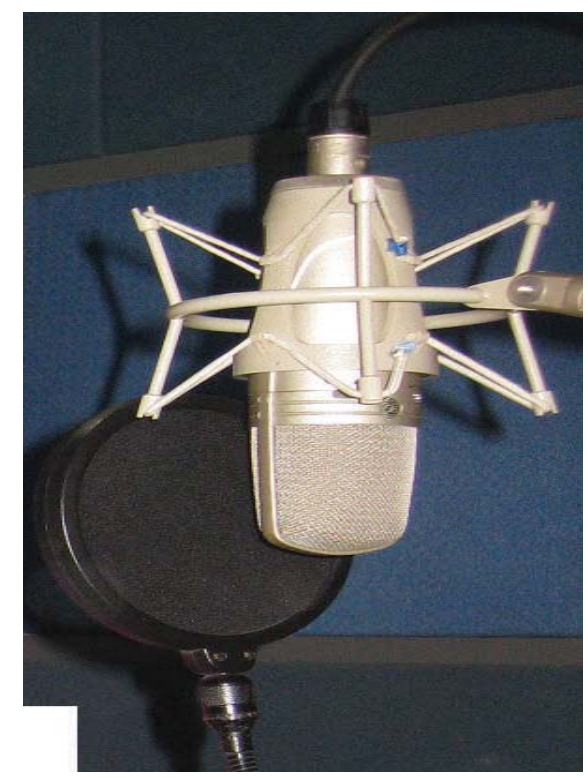

Gambar 2. Input Media yang di gunakan Jack's One Studio merk Shure Microphone (Sumber foto: Junita Batubara 2015)

Media audio controller adalah sebuah peralatan elektronik yang berfungsi memadukan (lebih populer dengan istilah "mixing"), pengaturan jalur (routing) dan merubah level, serta harmonisasi dinamis dari sinyal audio. Signal yang telah dirubah 
dan diatur kemudian dikuatkan oleh penguat akhir atau power amplifier. Pada umumnya ada beberapa menu yang terdapat pada mixer controller yaitu: gain, equalizer pada channel, dan swepable equalizer. Jack's One studio memakai input media (M-audio controller) merk Tascam dan memiliki 24 channel rauting out put (seperti pada gambar 3 ).

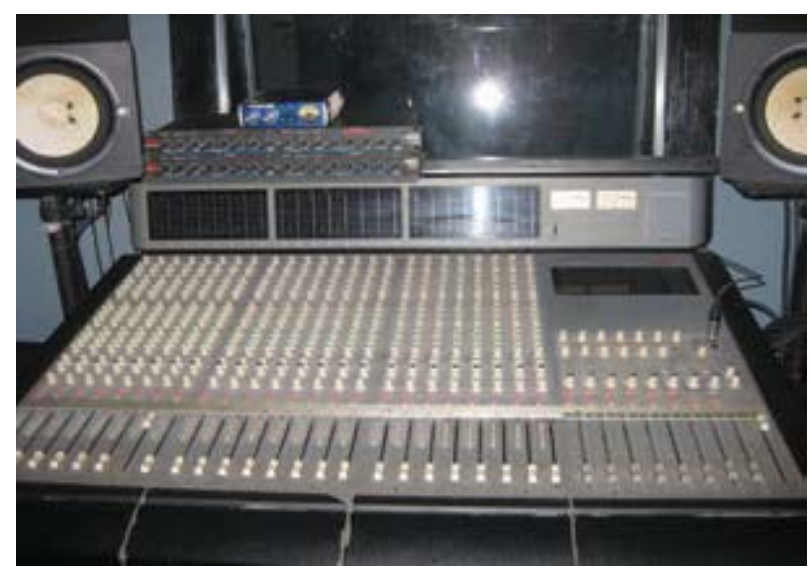

Gambar 3. Input Media (M-audio controller) yang berfungsi sebagai pengatur line instrumen musik. (Sumber: Junita Batubara, 2015)

Komputer merupakan syarat mutlak dalam rangkaian studio rekaman. Karena dapat dikatakan bahwa sumber teknologi, efek-efek, jenis suara, dan pengerjaan recording, mixing sampai dengan mastering, semuanya tersimpan dalam perangkat tersebut. Untuk spesifikasi komputer yang di pakai pada studio rekaman idealnya dibutuhkan beberapa perangkat seperti: intel processor dual core atau core 2 duo (recomended), mainboard intel, ram $1 \mathrm{~Gb}$ atau $2 \mathrm{~Gb}$ (recomended), monitor, dan sound card asio. Semakin besar kapasitas ram pada komputer yang dipakai pada studio rekaman maka semakin banyak software yang dapat diinstall dan semakin banyak ruang penyimpanan data.

Perangkat komputer yang dipakai Jack's One Studio cukup canggih dan memadai untuk menginstal program rekaman dan menyimpan data midi yang telah direkam. Fungsi soundcard yaitu untuk mengolah data berupa audio atau suara. Soundcard atau yang lebih dikenal dengan kartu suara adalah suatu komponen yang terdapat dalam PC yang bertugas untuk menunjang fungsi suara dalam PC multimedia dan mempunyai empat slot yang tersambung ke speaker yang bertujuan untuk mend engar hasil rekaman. Hal tersebut dapat dilihat pada gambar 4.

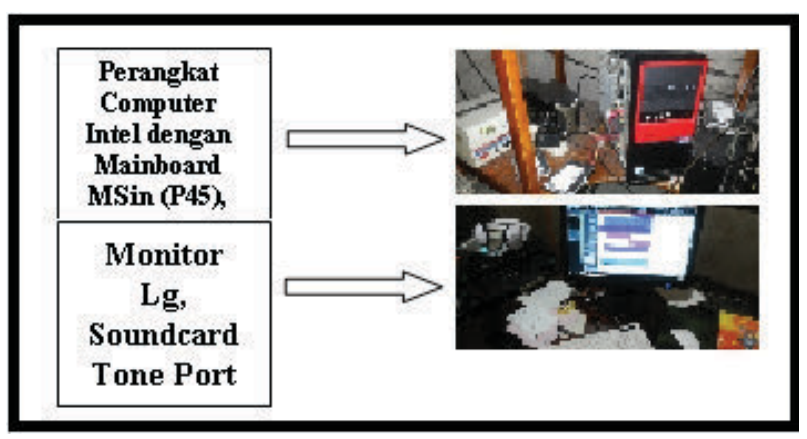

Gambar 4. Perangkat komputer yang digunakan di Jack's One Studio. (Sumber: Sombama, 2015)

Headphone berfungsi untuk memonitor hasil recording. Alat ini sangat berguna misalnya saat kita ingin take suara instrumen, sambil mendengarkan panduan pola musik yang sudah diaransemen. Dengan menggunakan headphone, musik akan terdengar lebih fokus. Jack's One studio memiliki headphone merk Samson dengan kualitas baik pada saat take vokal. Suara yang dihasilkan headphone tersebut setereo (seperti pada gambar 5).

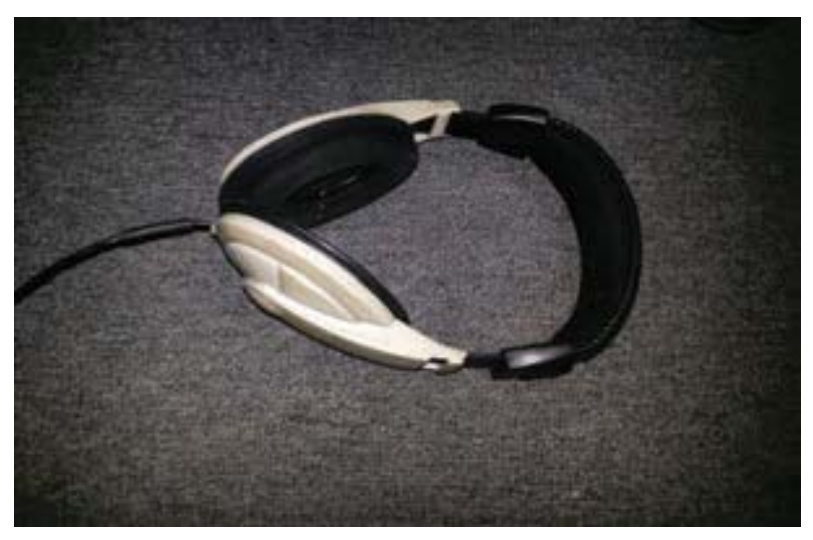

Gambar 5. Headphone merk Samson yang digunakan di Jack's One Studio (Sumber: Sombama, 2015)

Proses perekaman instrumental akustik untuk lagu O Tao Toba dan Pulo Samosir bersifat menggunakan hanya software Nuendo yang berfungsi untuk editing dan membuat mastering. Software Nuendo adalah salah satu software perekaman yang diproduksi oleh Steinberg. Jack's One studio menggunakan software Nuendo 06 dalam merekam audio dari mixer. Cara kerja Software Nuendo 06 sangat efisien dalam merekam lagu O Tao Toba dan Pulo 
Samosir karna fitur-fitur yang ditawarkan softwer tersebut sangat banyak dalam mengedit audio yang direkam dari mixer.

\section{Ruangan Studio Rekaman Jack's One}

Ruangan studio Jack's One dibagi atas tiga ruangan yaitu ruangan tunggu, ruangan Traking/ Takel Rekaman, dan ruangan kontrol/ruang Mixing, Editing, Mastering, Ruang Take studio Jack's One merupakan ruangan khusus untuk melakukan rekaman vokal dan alat musik. Dekorasi pada ruangan take tersebut terdiri dari beberapa Instrumen musik, input media, stand mic, head set, stand book dan mempunyai Live area dan dead area (seperti dalam tabel 2).

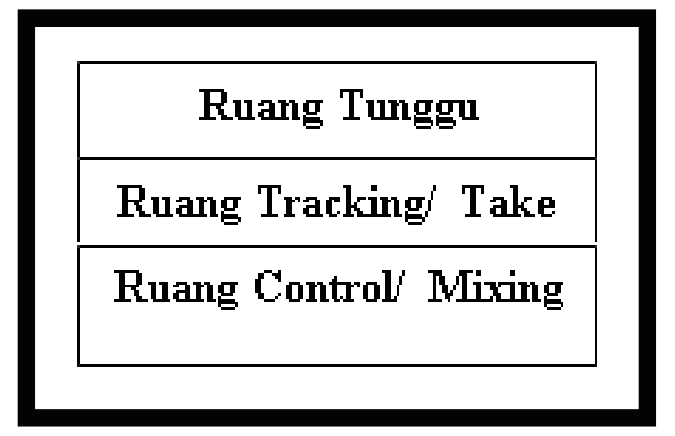

Tabel 2. Ruangan Yang Terdapat Pada Jack's One Studio (Sumber; Junita Batubara, 2015)

Ruangan rekaman adalah ruang studio musik yang cukup memantulkan suara, sementara dead area adalah area yang menyerap suara dan cenderung memperkuat suara bass dengan resonasi dindingnya agar ruangan tersebut tidak mengalami noise (dapat dilihat pada gambar 6).

Ruang kontrol/ ruang Mixing, Editing, dan Mastering (dapat dilihat pada gambar 7), merupakan ruangan untuk melakukan pengoperasian (mengontrol) sistem kerja alat-alat untuk rekaman baik secara track maupun live. Ruang ini membutuhkan standar ruang akustik. Tanpa ruang kedap suara kemungkinan proses rekaman menjadi panjang karena banyak suara yang bocor atau pun mengganggu masuk ke dalam rekaman dan merusak sebuah musik (lagu). Ruangan tersebut memerlukan penanganan akustik yang berbeda karena ruangan tersebut harus dapat mendukung tiap frekwensi suara yang bermacammacam dari alat-alat musik yang terlibat dalam proses rekaman.

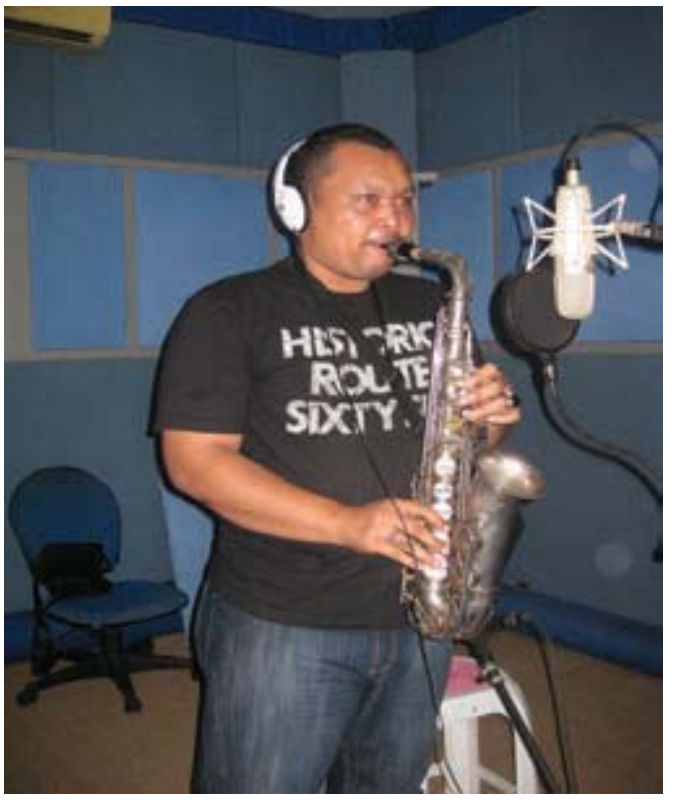

Gambar 6. Ruang Tracking/Take/Rekaman Jack's One Studio (Sumber: Junita Batubara, 2015)

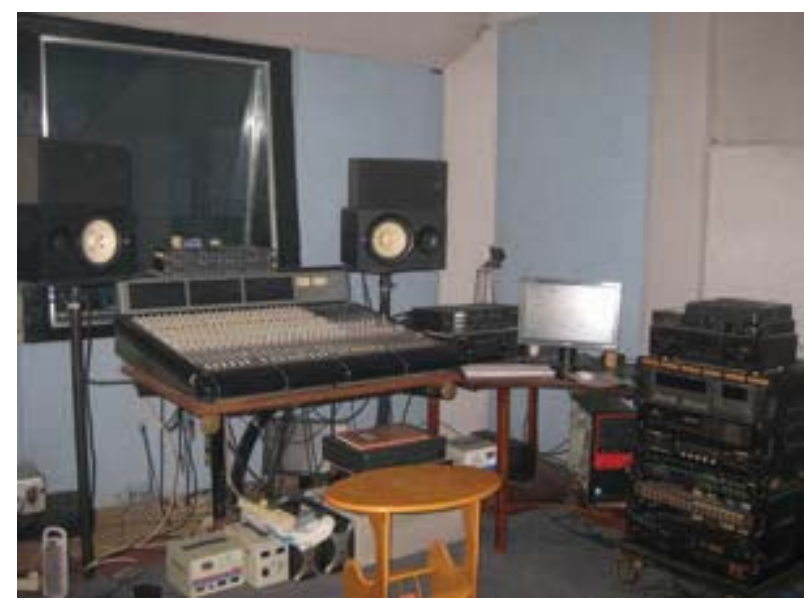

Gambar 7. Ruang kontrol/ ruang Mixing, Editing, dan Mastering Jack's One Studio (Sumber: Junita Batubara, 2015)

Studio Jack's One studio memiliki ruangan tunggu dan sekaligus ruangan kantor yang berada di belakang studio. Ruangan ini berfungsi untuk melaksanakan semua administrasi dan sekaligus juga sebagai ruang tamu yang dilengkapi dengan perlengkapan penunjang untuk memantau ke dua ruangan lain, ruangan tersebut disediakan agar dapat memantau proses selama latihan maupun rekaman. 


\section{Instrumen Musik Yang Digunakan Oleh Jack's One Studio Dalam Proses Recording Lagu O Tao Toba dan Pulo Samosir}

Alat musik yang digunakan dalam recording musik O Tao Toba dan Pulo Samosir di studio Jack's One yaitu Saxophone alto, Sulim, Gitar Akustik, Gitar elektrik, Cazon, dan software musik Nuendo06. Tahapan awal yaitu pembuatan bagan musik memakai software kemudian langsung melakukan perekaman secara "live" (seseorang pemain yang langsung direkam). Tujuan pembuatan bagan/repertoar musik, agar Instruktur studio mengetahui apa saja instrumen musik yang akan direkam secara langsung. Yang dimaksud direkam secara live/langsung yaitu instrumen musik direkam satu per satu untuk Filler (mengisi) bagian atau repertoar musik yang telah disediakan. Instrumen musik yang paling berperan dalam recording adalah instrumen musik Saxophone alto dimana instrumen tersebut sebagai pembawa melodi dalam kedua-dua lagu tersebut di atas, dapat dilihat pada gambar 8 .

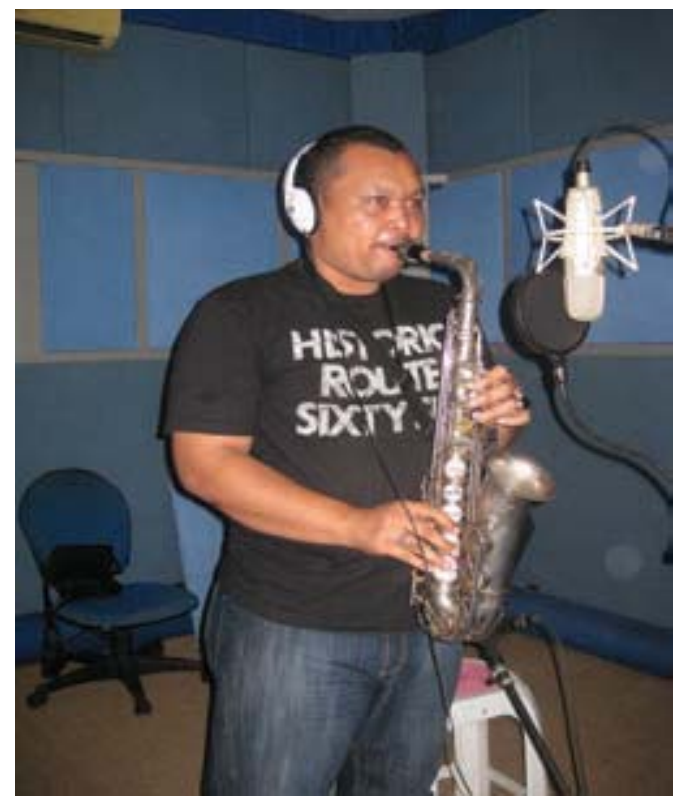

Gambar 8. Instrumen saxophone alto yang dibawakan oleh Sombama Tambunan dalam proses recording lagu $O$ Tao Toba dan Pulo Samosir (Sumber: Junita Batubara, 2015).

Instrumen musik sulim (dapat dilihat dalm gambar 9) adalah alat musik trdisional Batak Toba yang terbuat dari bambu dengan teknik permainan ditiup.
Fungsi alat musik sulim dalam recording musik $O$ Tao Toba adalah sebagai pembawa intro atau pembuka awal lagu sebelum masuk ke tema lagu. Ide instruktur rekaman dengan memasukkan instrumen sulim dalam mengisi lagu tersebut di atas, bertujuan menciptakan suasana 'kerinduan' sekitaran pinggiran Danau Toba diikuti dengan efek suara riak air yang direkam langsung dari Danau Toba.

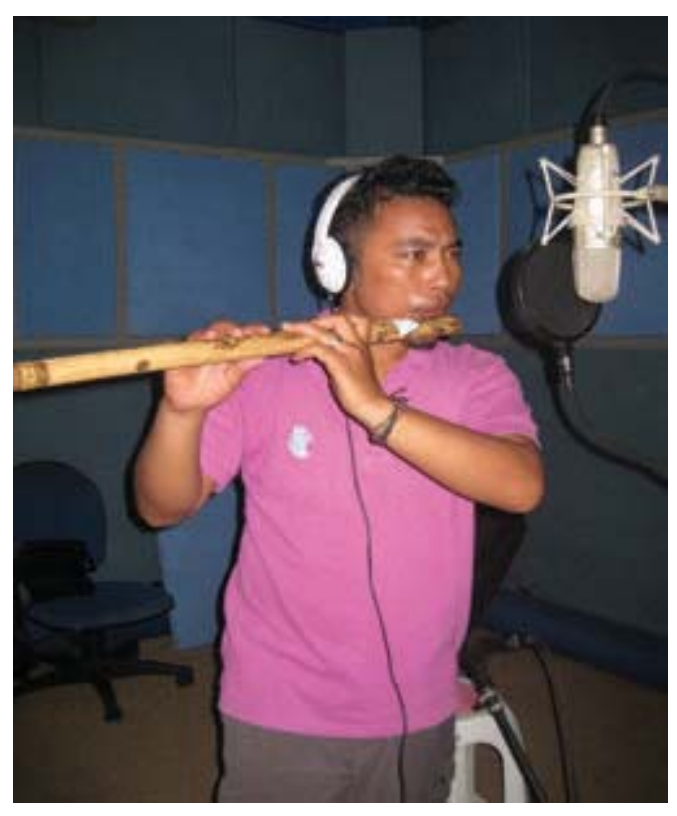

Gambar 9. Instrumen musik Sulim yang dimainkan oleh Juniro Sitanggang dalam proses recording musik O Tao Toba (Sumber: Junita Batubara, 2015).

Alat musik cazon adalah alat musik perkusi berbentuk persegi dimana alat musik cazon termasuk dalam keluarga membranophone. Fungsi alat musik Cazon dalam recording musik $O$ Tao Toba dan Pulo Samosir adalah sebagai pembawa ritem. Pemilihan alat musik cazon untuk kedua-dua lagu tersebut adalah untuk memperkuat suasana sedang bermain musik ditepi pantai, dan instrumeninstrumen musik yang disajikan adalah bersifat akustik (seperti dalam gambar 10). 


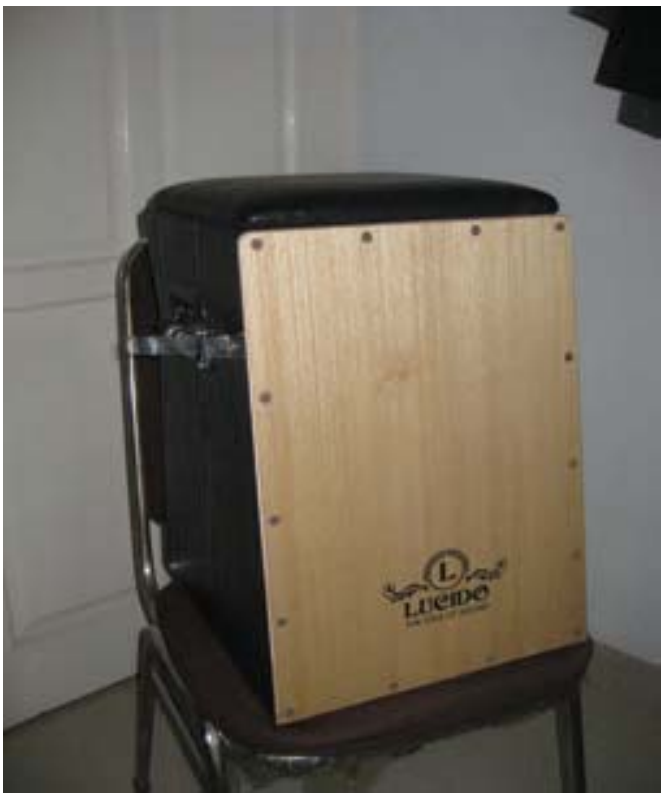

Gambar 10. Instrumen musik Cazon yang dimainkan dalam proses recording lagu O Tao Toba dan Pulo Samosir. (Sumber: Junita Batubara, 2015)

Instrumen gitar akustik (dapat dilihat dalam gambar 11) dalam recording musik O Tao Toba dan Pulo Samosir adalah sebagai pembawa akord. Begitu juga dengan alat musik gitar elektrik adalah sebagai 'mempertebal'suara akord sehingga arransemen musik pada lagu O tao Toba dan Pulo Samosir kedengaran seperti musik modern tetapi tetap menggambarkan suasana disekitaran pinggiran Danau Toba.

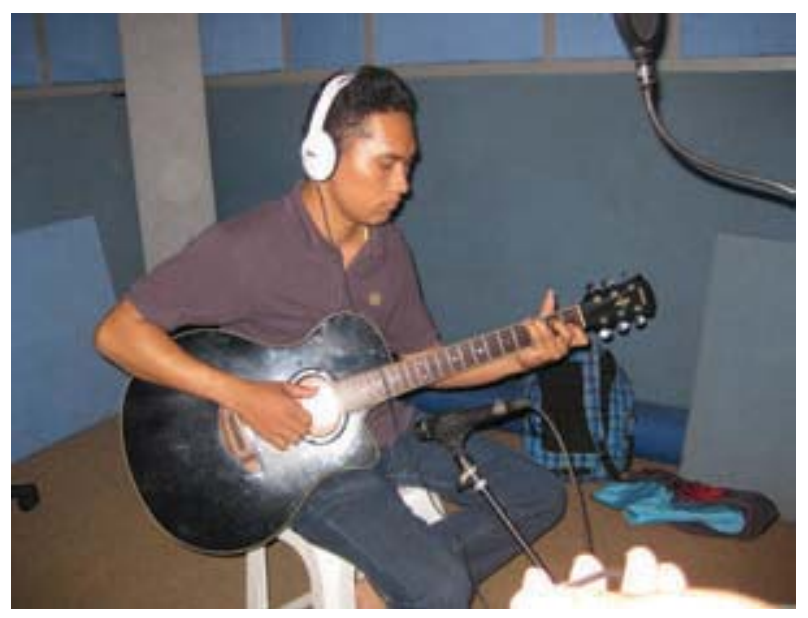

Gambar 11. Instrumen musik Gitar Akustik yang dimainkan oleh Agus Lumban Gaol dalam recording sebagai pembawa akord (Sumber: Junita Batubara, 2015).

\section{Hasil Recording Lagu $O$ Tao Toba dan Pulo Samosir Dengan Format Musik Instrumental Akustik Yang Dilakukan Jekonia Sembiring}

Untuk mendapatkan hasil rekaman yang maksimal dibutuhkan beberapa proses. Setiap proses sangat mempengaruhi hasil rekaman akhir. Studio Jack's One mempunyai empat tahapan dalam proses perekaman untuk mendapatkan hasil rekaman yang baik yaitu; preparation (persiapan), recording (rekaman), mixing (penyelesaian), mastering (hasil). Kemajuan teknologi pada era saat ini membuat cara kerja arransemen musik sudah sangat canggih dan cepat. Pembuatan musik pada lagu $O$ Tao Toba dan Pulo Samosir berikut ini sudah memakai software. Software yang digunakan dalam arransemen lagu tersebut yaitu: M-Audio Controller, Windows 7 (Sistem Operasi), dan Nuendo 06 (Media Perekam).

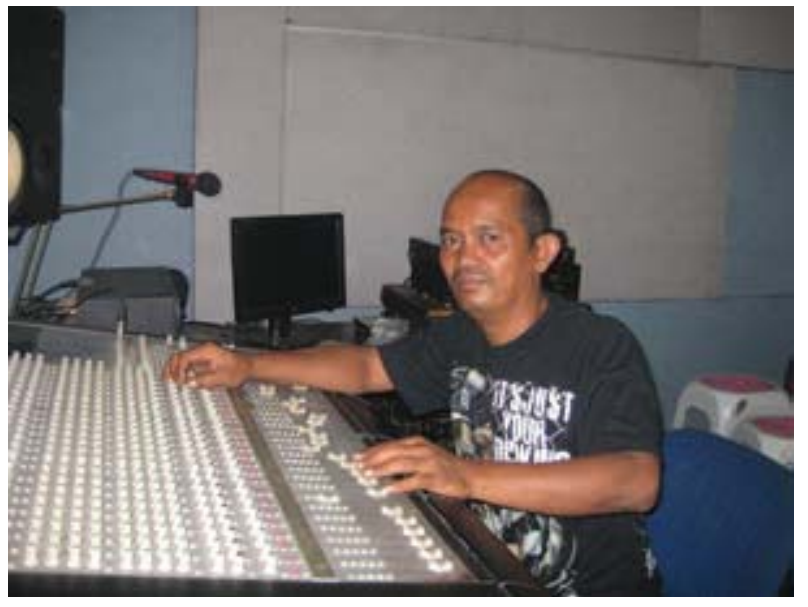

Gambar 13. Instruktur/Jekonia Sembiring sedang melakukan $M$-Audio Controller pada lagu O Tao Toba dan Pulo Samosir (Sumber: Junita Batubara, 2015)

Dalam proses recording yang dilakukan Jekonia Sembiring pasti ada saja kendala-kendala yang dihadapi pada proses recording lagu $O$ Tao Toba dan Pulo Samosir, baik itu dalam proses aransemen lagu dan proses take instrumen. Namun semuanya dapat teratasi dengan baik. Proses dalam recording lagu O Tao Toba dan Pulo Samosir dari awal hingga selesai dilakukan dalam dua season. Satu season dihitung per-enam jam dalam penggunaan studio rekaman. Kendala yang dihadapi instruktur bahkan pemain yaitu banyak terdapat pengulangan-pengulangan untuk setiap instrumen yang direkam 
dan pengeditan suara setiap instrumen agar lebih jernih.

Salah satu tahap yang paling penting dalam mendapatkan hasil rekaman yang maksimal adalah persiapan. Dalam tahap awal perekaman, seorang instruktur rekaman harus mengetahui genre lagu yang direkam. Lagu yang ditentukan adalah lagu ciptaan Nahum Situmorang yang berjudul $O$ Tao Toba dan Pulo Samosir. Kedua-dua lagu tersebut termasuk genre/era musik popular Batak Toba tahun 1946-an yang dipengaruhi irama musik Amerika Latin seperti Slow-fox dan slow calypso. Nada dasar asli dari lagu $O$ Tao Toba yaitu dari Es= do dan lagu Pulo Samosir yaitu dari $\mathrm{D}=$ do. Pada lagu $O$ Tao Toba, ada perubahan yang dilakukan oleh instruktur yaitu tempo lagu tersebut $=68$, dengan nada dasar $\mathrm{Bb}=$ do untuk instrumen musik gitar akustik dan gitar bass, dan pada instrumen saxophone sebagai pembawa melodi menjadi nada dasarnya $\mathrm{G}=\mathrm{do}$; birama 4/4; irama musik slow-fox dan kontur Statis \& Terraced. Irama musik Fox-Trot/Slow Fox adalah jenis irama tarian dari Amerika Serikat yang popular sekitar tahun 1912. Kontur atau garis melodi adalah garis melodi yang sifatnya tetap bergerak dalam ruang lingkup datar kemudian berjenjang dari nada yang lebih rendah ke nada yang lebih tinggi.Tarian dalam birama biner ini akrab dengan musik jazz, namun dalam perkembangannya menjadi dua macam yang bertempo cepat dan lambat.

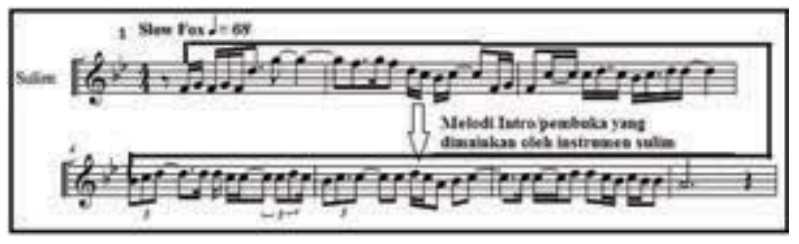

Gambar 12. Transkrip notasi intro yang dimainkan oleh sulim pada lagu $\mathrm{O}$ Tao Toba pada nada dasar $\mathrm{Bb}=\mathrm{do}$ (Sumber: Junita Batubara, 2015)

Sebelum memasuki tahap recording instruktur menuangkan ide untuk mengaransemen ulang lagu $O$ Tao Toba dengan membuat bagan lagu. Fungsi dari pembuatan bagan lagu adalah untuk mengetahui berapa bar lagu tersebut untuk intro dan berapa dari awal hingga ending lagu tersebut. Sulim dari Bar 1-7 dengan nada dasar $\mathrm{Bb}=$ do sebagai intro diiringi instrumen cazon dengan membawa ritem konstan, gitar akustik dan gitar bass membawa akord. Hal tersebut dapat dilihat pada gambar 14.

$$
\text { ..I. |I...|.V..|...I.| II.V.|.I..|..V7.|" }
$$

Gambar 14. Bagan Intro Instrumen Musik Sulim Dengan tingkatan akord

Saxophone dengan nada dasar GM dimulai dari bar 8-56 membawa melodi diiringi oleh instrumen musik cazon, gitar akustik dan gitar bass dengan nada dasar Bb sebagai pembawa akord atau pengiring melodi. Bagan ini dapat dilihat pada gambar 15.

|...F7.|Bb....|.....dmAug...

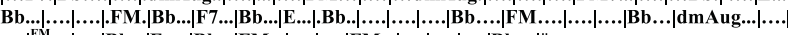

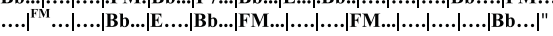

Gambar 15. Bagan iringan akord lagu O Tao Toba yang dibawakan Instrumen gitar akustik dan gitar bass (Sumber: Junita Batubara, 2015)

Pada lagu Pulo Samosir, juga dilakukan pembuatan bagan dengan rincian yang hampir sama dengan rincian lagu $O$ Tao Toba. Hanya saja pada bagian ini, yang melakukan intro awal adalah saxophone. Pada lagu tersebut. Pada Lagu Pulo Samosir $=100$ dengan nada dasar Es=do. Kemudian Instruktur tetap menggunakan nada dasar aslinya tetapi pada Lagu Pulo Saamosir, instruktur mengubah nada dasar lagu agar pemain saxophone lebih mudah menjangkau nada-nada tinggi (extra tone) di bagian improvisasi pada lagu tersebut yaitu menjadi bernada dasar Es=do. Lagu O Tao Toba. Dengan Tahap akhir pada persiapan adalah arransemen. Kemudian lagu Pulo Samosir berirama 4/4 dengan irama musik slow calypso dan kontur Pendulous.

Setelah selesai pembuatan bagan musik, dilanjutkan ke tahap perekaman setiap alat musik yang dimainkan sampai pada ending lagu. Teknik permainan gitar akustik pada perekaman musik $O$ Tao Toba yaitu dengan teknik blok akord dan gitar bass sebagai drone untuk 'mempertebal' suara akord-akord dengan cara bass berjalan/bassocontinuo. Sulim membawakan melodi secara improvisasi seperti melodi andung. Cazon membawakan ritem konstan dari awal hingga akhir lagu.

Proses pembuatan dasar musik atau yang sering disebut "musik mentah" pada pembuatan musik $O$ 
Tao Toba yang direkam secara satu-persatu seperti sulim, saxophone, gitar akustik, gitar bass dan cazon secara 'live'. Pertama-tama yang direkam adalah melodi yang dimainkan saxophone, kemudian diikuti gitar akustik. Selanjutnya memberikan improvisasi disaat intro yang dimainkan oleh sulim. Bagian akhir dari perekaman adalah untuk instrumen musik gitar bass dimana fungsi gitar bass pada lagu tersebut adalah sebagai drone atau mempetebal akord-akord yang dimainkan instrumen musik gitar akustik.

Setelah mendapatkan bagan musik dan hasil 'musik mentah' dalam bentuk midi, tahap yang berikutnya mengubah midi menjadi MP3 dengan Converting Midi ke MP3. Tahapan selanjutnya yaitu recording (rekaman). Hasil wawancara pada tanggal 29 Juni 2015 di Jack' One Studio, Jekonia mengatakan bahwa saat sedang merekam, sound yang diinginkan minimal $70 \%$ sudah terbentuk, dan ditunggu sampai proses mixing.

Proses rekaman sebuah lagu dimulai dengan membuat Click Track (metronome) dengan tempo lagu yang sudah ditentukan sebelumnya. Lagu $O$ Tao Toba dengan tempo 68 dan memiliki birama 4/4. Fungsi dari Metronome adalah untuk membantu pemain agar temponya tidak lari (kejar-kejaran). Walaupun akord pada lagu dan pukulan cazon sudah direkam, tetap harus menggunakan metronome mengantisipasi agar seluruh Instrumen nantinya seirama seusai tempo. Perekaman berikutnya yaitu perekaman instrumen sulim. Ada satu bagian saja yang harus diisi oleh instrumen sulim pada lagu O Tao Toba yaitu pada intro awal lagu. Seterusnya perekaman Instrumen saxophone. Instrumen saxophone adalah instrumen yang paling inti pada lagu tersebut, karena saxophone menjadi melodi utama yang menggantikan vokal, jadi implementasi pada syair lagu dibawakan oleh instrumen saxophone. Ada dua bagian yang diisi saxophone yaitu pembawa melodi, pengulangan pada bagian reff, dan improvisasi sebelum ending lagu.

Selanjutnya perekaman instrumen cazon, Instrumen cazon dalam musik $O$ Tao Toba adalah Instrumen pendukung. Fungsi cazon dalam musik $O$ Tao Toba yaitu pemberi nuansa musik batak, selain itu sebagi pembawa ritem drum. Perekaman cazon dimulai dari intro lagu hingga pada ending lagu. Bagian akhir perekaman adalah untuk Instrumen gitar akustik dan elektrik. Fungsi gitar akustik dan elektrik pada musik $O$ Tao Toba yaitu sebagi pembawa akord atau sebagai pengiring saxophone dalam membawakan melodi.

Setelah seluruh permainan telah direkam, maka proses selanjutnya yaitu mixing. Mixing adalah proses membalance, EQ, dan mengedit track yang telah direkam sebelumnya agar hasilnya lebih baik. Proses penambahan FX pada track yang telah direkam dilakukan pada tahap mixing. Proses mixing bukan untuk memperbaiki sound yang buruk dari track yang telah direkam. Jika ingin memperbaiki track yang soundnya buruk, lebih baik di take (rekam) ulang.

Setelah memasukkan seluruh chanel sound yang digunakan pada track-track pada mixer, langkah selanjutnya adalah pengaturan dan pemberian efek. Melalui mixer pengaturan EQ bisa dilakukan dengan lebih detail dibanding pengaturan EQ melalui channel setting. Pada mixer dimungkinkan untuk melakukan pengaturan EQ dari frequency dan width, sehingga lebih maksimal. Grafik pada pengaturan EQ mixer pun lebih mudah digunakan.

Melalui mixer pengaturan EQ bisa dilakukan dengan lebih detail dibanding pengaturan EQ melalui channel setting. Pada mixer dimungkinkan untuk melakukan pengaturan EQ dari frequency dan width, sehingga lebih maksimal. Grafik pada pengaturan EQ mixer pun lebih mudah digunakan. Pemberian efek disini dimaksudkan untuk menghasilkan sound yang lebih baik lagi. Untuk memberikan efek, gunakan rak-rak efek pada mixer. Klik segitiga pada rak dan kemudian pilih Select. Setelah muncul tampilan efek, pilih salah satu dari tampilan efek tersebut.

Tahap yang paling akhir yaitu Mastering dengan menggunakan nuendo 06. Mastering bertujuan untuk membuat hasil mixing yang sudah baik menjadi lebih baik. Hasil rekaman menjadi lebih lebar dan levelnya menjadi lebih besar. Mastering merupakan tahap terakhir dimana lagu yang sudah jadi diolah lagi agar sound yang dihasilkan lebih halus dan tidak noise, yaitu dengan mengkompres frekuensi-frekuensi yang kasar, memoles dan meratakan, menetapkan standar volume. 


\section{SIMPULAN}

Studio rekaman merupakan suatu wadah untuk meng-expresikan diri seseorang di bidang seni musik maupun hiburan. Kota Medan merupakan kota terbesar ke-3 di Indonesia dan merupakan kota metropolitan. Masyarakat Kota Medan merupakan masyarakat yang kreatif, khususnya di bidang budaya maupun musik. Sehingga banyak lahir seniman-seniman dari Kota Medan yang cukup terkenal di Indonesia maupun di manca negara.

Berbicara tentang studio rekaman di Kota Medan, studio rekaman sudah di kenal di kota medan sejak tahun 90-an. Salah satu studio rekaman yang sudah lama berdiri dan sudah lama menggeluti Mixing di Kota Medan adalah Jack's One Studio, yang beralamat di Jalan Karya Sembada No. 260 (Koserna Padang Bulan) Medan. Ada beberapa tahapan yang harus diperhatikan dalam proses perekaman musik di Jack's One Studio untuk mendapatkan hasil yang maksimal dan baik yaitu: Preparation (Persiapan), Recording (Rekaman), Mixing, Mastering. Selain pemain musik yang harus dituntut untuk propesional dalam mengiringi musik yang direkam, seorang Instruktur studio rekaman juga harus dituntut untuk sangat propesional.

Dalam proses perekaman lagu O Tao Toba dan Pulo Samosir tahapan-tahapan tersebut digunakan, dengan tujuan agar mendapat hasil rekaman yang maksimal. Fasilitas rekaman yang disediakan oleh Jack's One Studio cukup lengkap. Dalam proses perekaman pembuatan bagan musik $O$ Tao Toba dan Pulo Samosir memakai software Nuendo 06 untuk proses mixing.

Selain itu walaupun peralatan di Jack's One Studio sudah cukup canggih, hal tersebut tidak terlepas oleh peran seorang Instruktur studio rekaman, karena kunci dari hasil rekaman baik buruknya nantinya di tangan Instruktur. Tugas Instruktur sangat rumit, seorang Instruktur studio rekaman harus jeli mendengar suara falseet pada saat proses rekaman, mengarahkan seorang pemain pada saat proses perekaman, dan harus mampu mengatur frekwensi suara pada saat proses perekaman.

Dari beberapa hasil kesimpulan di atas, ada beberapa saran yang berhubungan dengan proses recording pada studio recording, hendaknya komputer musik dengan menggunakan berbagai software yang digunakan untuk recording lebih diperdalam lagi pembelajarannya pada setiap instansi pendidikan yang memiliki jurusan seni musik. Ini sangat memperkuat skill dalam membuka lowongan pekerjaan sendiri atau wirausaha. Kemudian agar artikel ini dapat dilanjutkan sehingga pengetahuan recording semakin berkembang. Diharapkan kepada para seniman yang pernah melakukan rekaman musik studio dapat membuat tulisan tentang proses dan teknik rekaman studio yang baik. Rekaman musik studio yang baik akan mendapatkan hasil yang maksimal yang dapat dinikmati oleh masyarakat dan para pendengarnya serta menimbulkan kebanggan tersendiri bagi para pelakunya.

\section{DAFTAR RUJUKAN}

Bangun, Jabatin. (2005), Ilmu Pengetahuan Dan Seni, dalam Jurnal Etnomusikologi Vol.1 (2) :97-99. Universitas Sumatera Utara Medan. Indonesia.

Godfrey. (1993), Music Since 1945: Issues, Materials and Literature. Belmont, California: Cencage Learning.

Hodges, W.R. (2009), Ganti Andung, Gabe Ende (Replacing Laments, Becoming Hymns): The Changing Voice of Indonesia). A Dissertation Submitted in partial Satisfaction of the Requirements for the Degree Grief in the Pre-funeral Wakes of Protestant Toba Batak, North Sumatra, Doctor of Philosophy in Music, University of California.

Komputer, Wahana. (2014), Adobe Audition CS6. Semarang: Penerbit Andi.

Malm, W.P. 1967. Music Cultures of The Pasific Music The Near East and Asia.Prentice Hall Inc. Englewood Cluffs, New Jersey.

Merriam, William P. (1964), The Anthropology of Music. Northwestern University Press. Chicago.

Nettl, Bruno. (1964), Theory and Method in Ethnomusicology. The Free Press, A Division of Macmillan Publishing Co. Inc. New York. 
Pramudyanto, Beny, Alexander. (2013), Hegemonyatas Dominasi Logika Industri Musik (Studi Kasus Perkembangan Netlabel di Indonesia), dalam Jurnal Komunikasi Media Baru dan Peluang Counter Vol 10, No. 1:63-65. Universitas Indonesia. Jakarta.

\section{Sumber Internet:}

Hsutadi. (2010), "Sejarah Industri Musik dan Rekaman Indonesia" 26 November 2014. (http://fortisrecord.wordpress.com)

Indaq. (2012), “Apa Fungsi dan Kegunaan Dibox Direct" 26 November 2014.

(http://www.distorsiaudio.com)

Mangkat. (2013), "Manfaat Dan Kegunaan Equalizer" 20 februari 2015.

(http://grasakfuckaudio.blogspot.com)

Nurdiana. (2012), "Menggunakan Nuendo Untuk Merekam Dan Editing Audio" 20 februari 2015 (https://nughairstudio.wordpress.com)
Pratiwie. (2009), "Sejarah Rekaman Dan Alat Perekam" 23 November 2014.

(http://gitapratiwie.wordpress.com)

Petra. (2012), "Proses Produksi Sebuah Lagu (Secara Umum)" 10 Febuari 2015 (http://rekam,musik.blogspot.com)

Purnomo. (2009), "Reason 401 Software Ajaib Untuk Studio" 24 febuari 2015

(http://ssokoj.blogspot.com)

Redyafrians. (2011), "Melodyne Software Pitch Correcting Terbaik" 26 febuari 2015

(http://blog.rumahrekam.com)

Situmorang. (2010), "Lelaki yang Ingin Dikubur di Samosir itu Bernama Nahum Situmorang" 28 November 2014 (http://tanoBatak.wordpress.com)

Sumendong. (2012), "Pengenalan FruityLoop Studio" 26 Febuari 2015 (http://dats.blogspot.com) 